\title{
ATRIBUTOS FÍSICOS E DESEMPENHO AGRONÔMICO DA CULTURA DA SOJA EM UM LATOSSOLO VERMELHO DISTROFÉRRICO SUBMETIDO A DOIS SISTEMAS DE MANEJOS ${ }^{1}$
}

\author{
Physical attributes and performance of soybean in Oxisol under two management systems ${ }^{1}$
}

\author{
Fábio Régis Souza 2 , Edgard Jardim Rosa Junior ${ }^{3}$, Carlos Ricardo Fietz ${ }^{4}$, \\ Anderson Cristian Bergamin ${ }^{3}$, Luciano dos Reis Venturoso ${ }^{3}$, Yara Brito Chaim Jardim Rosa ${ }^{3}$
}

\begin{abstract}
RESUMO
Os sistemas de manejo agindo com condicionadores do solo podem alterar a qualidade física do solo e restringir ou maximizar a produção agrícola. Objetivou-se com este estudo avaliar os atributos físicos e o desempenho agronômico da cultura da soja em um Latossolo Vermelho distroférrico submetido a dois sistemas de manejos em Dourados-MS. O delineamento experimental foi em blocos casualizados, em esquema de parcelas subsubdivididas, sendo dois sistemas manejo do solo nas (parcelas) com 0 e $2000 \mathrm{~kg} \mathrm{ha}^{-1}$ de gesso agrícola (subparcelas) e cinco profundidades $(0-0,05,0,05-0,10,0,10-0,15,0,15-0,20$ e $0,20-0,30 \mathrm{~m}$, sendo as subsubparcelas) com quatro repetições. Foram avaliados atributos físicos do solo e desempenho agronômico da cultura da soja. Os resultados mostram que a densidade do solo foi maior no plantio direto. A macroporosidade foi maior na profundidade de $0-0,05 \mathrm{~m}$ no plantio convencional e a microporosidade aumentou com a profundidade nos sistemas de manejo. A resistência à penetração aumentou em maiores profundidades. O plantio direto reduziu o número de vagens e o efeito residual de gesso aumentou a altura final das plantas.
\end{abstract}

Termos para indexação: Plantio direto, plantio convencional, Glycine max (L.) Merr.

\begin{abstract}
Management systems acting with soil conditioners can change the physical quality of the soil and restrict or maximize agricultural production. In this study, we assessed the effect of the tillage system with and without the gypsum residual effect at different depths in a dystrophic red Oxisol in Dourados, State of Mato Grosso do Sul, Brazil. The experimental design was randomized blocks with arrangements of subdivided plots; the treatments were two soil manure systems, in plots and with 0 and $2000 \mathrm{~kg} \mathrm{ha}^{-1}$ gypsum (subplots) and five depths $(0-0.05,0.05-0.10,0.10-0.15,0.15-0.20$, and $0.20-0.30 \mathrm{~m}$, the latter ones being the subplots) with four replicates. Physical attributes of the soil and agronomic performance of soybean crop were evaluated. The results show that the soil density was higher in tillage system and the gypsum residual effect influenced the soil density at $0.10-0.15$ $\mathrm{m}$ deep. The macro porosity was higher at $0-0.05 \mathrm{~m}$ deep in conventional sowing and the micro porosity increased with the depth in the manure systems. The penetration resistance increased in higher depths. The tillage system with reduced pod number and gypsum residual effect increased the plant height.
\end{abstract}

Index terms: No tillage, conventional tillage, Glycine $\max ($ L.) Merr.

(Recebido em 1 de fevereiro de 2010 e aprovado em 14 de setembro de 2010)

\section{INTRODUÇÃO}

A soja é cultivada em diversos locais do Mato Grosso do Sul. Em grande parte dessas regiões, os solos apresentam características de cerrado, que em condições em que não ocorreu ação do homem possuem boas características físicas.

O uso do solo para produção agrícola no cerrado se intensificou, segundo Costa et al. (2006), nos últimos 30 anos. Esse processo ocorreu com o emprego de sistemas de preparo intensivo do solo, devido à necessidade de incorporação de restos da vegetação nativa, corretivos e fertilizantes. Porém, com a intensificação do preparo, os atributos físicos do solo foram alterados conforme o manejo aplicado. Geralmente esse processo é agravado pelo constante uso de implementos e tráfego agrícola utilizados no preparo convencional (Spera et al., 2004).

Adoções de técnicas agrícolas que maximizem os recursos, reduzam custos de produção, melhorem a produtividade, permitindo qualidade ambiental, têm-se tornado cada vez mais importantes para o sistema produtivo (Gupta et al., 2002; Hobbs \& Gupta, 2003).

O plantio direto assume essa prerrogativa (Bayer et al., 2006) por fornecer um alto aporte de palha que resulta

\footnotetext{
${ }^{1}$ Parte da Dissertação de Mestrado do primeiro autor apresentada ao Programa de Pós-Graduação em Agronomia da Universidade Federal da Grande Dourados/UFGD

${ }^{2}$ Centro Universitário da Grande Dourados - Rua Balbina de Matos - 2121 - Jardim Universitário - 79824-900 - Dourados, MS fabioagronomo@yahoo.com.br

${ }^{3}$ Universidade Federal da Grande Dourados/UFGD - Dourados, MS

${ }^{4}$ Empresa Brasileira de Pesquisa Agropecuária/Embrapa - Agropecuária Oeste/CPAO - Dourados, MS
} 
na melhoria da estabilidade de agregados redução das temperaturas máximas adequação do espaço poroso (aumentando a infiltração e retenção de água), difusão de oxigênio as raízes das culturas e maior resistência do solo à compactação.

A compactação do solo pode ser avaliada por meio de algumas propriedades físicas, tais como, densidade do solo e resistência do solo à penetração (Maria et al., 1999). A resistência do solo à penetração tem sido usada por apresentar melhores correlações com o crescimento radicular (Taylor \& Gardner, 1963), por ser uma propriedade sensível ao manejo, além de ter relação direta com o crescimento radicular e com a produtividade das plantas (Bengough et al., 2001). A resistência do solo à penetração, por sua vez, mantém relações intrínsecas com o conteúdo de água, densidade do solo e composição granulométrica (Beutler et al., 2006).

A aplicação de gesso agrícola possibilita melhores condições do subsolo, podendo atuar, de certa forma, como descompactante do solo (Raij, 2008), ambiente que geralmente é pouco favorável às raízes. O gesso atua diminuindo a saturação por alumínio e aumentando os teores de cálcio e enxofre (Vitti et al., 2008). A gessagem pode atuar como condicionador das estruturas do solo (Rosa Junior \& Vitorino, 1994; Rosa Junior et al., 2006), favorecendo a agregação, e consequente melhoria na estrutura do solo. Há ainda outros atributos físicos como densidade do solo e porosidade, que podem ser alterados pela combinação do sistema de manejo e a gessagem (Costa et al., 2007).

Considerando a importância de se conhecer e entender a influência do manejo do solo combinado com gesso agrícola, realizou-se esse trabalho com os objetivos de avaliar os atributos físicos e o desempenho agronômico da cultura da soja em um Latossolo Vermelho distroférrico submetido a dois manejos e presença e ausência de residual de gesso agrícola.

\section{MATERIAL E MÉTODOS}

O trabalho foi conduzido em uma área cedida em regime de comodato à Faculdade de Ciências Agrárias da Universidade Federal da Grande Dourados, localizada nas coordenadas $22^{\circ} 12^{\prime} 42,74^{\prime \prime} \mathrm{S}$ e $54^{\circ} 56^{\prime} 17,26^{\prime \prime} \mathrm{W}$, com altitude de 452 metros. O clima é do tipo Cwa, segundo a classificação de Köppen. O solo do local do experimento é classificado como Latossolo Vermelho Distroférrico, originalmente sob vegetação de cerrado. A área, cuja vegetação predominante era de gramíneas, nunca havia sido cultivada anteriormente. A vegetação natural foi inicialmente incorporada ao solo com aração e grade pesada.

Os atributos químicos do solo, observados no início da implantação dos sistemas de manejos na profundidade de 0-20 cm, apresentavam a seguinte fertilidade: $\mathrm{pH}$ em
$\mathrm{CaCl}_{2}(4,2) ; \mathrm{Al}\left(1,12 \mathrm{cmolc} \mathrm{dm}^{-3}\right) ; \mathrm{H}+\mathrm{Al} \mathrm{10,5}\left(\mathrm{cmolc} \mathrm{dm}^{-3}\right)$; $\mathrm{P}\left(2,0 \mathrm{mg} \mathrm{dm}{ }^{-3}\right) ; \mathrm{K}\left(0,2 \mathrm{cmolc} \mathrm{dm}^{-3}\right) ; \mathrm{Ca}\left(2,16 \mathrm{cmolc} \mathrm{dm}^{-3}\right)$; $\mathrm{Mg}\left(1,7 \mathrm{cmolc} \mathrm{dm}^{-3}\right) ; \mathrm{S}\left(5,5 \mathrm{mg} \mathrm{dm}^{-3}\right)$ pelo extrator $\mathrm{Ca}$ $\left(\mathrm{H}_{4} \mathrm{PO}_{4}\right)^{2}$ e saturação de bases $(28 \%)$. Foram realizadas as correções do solo e da fertilidade necessárias antes de iniciar a semeadura das culturas, visto que, após o estabelecimento do sistema plantio direto, as futuras correções seriam feitas na superfície do solo, sem incorporação.

O gesso foi aplicado a lanço e incorporado ao solo com grade niveladora, na primeira quinzena de outubro de 2003, tanto para o plantio direto quanto para o convencional. No sistema de manejo adotado com preparo do solo convencional, as operações consistiam em uso de uma grade intermediária, para o preparo primário e de uma grade niveladora, para o preparo secundário, isso ocorria sempre antes da semeadura da cultura.

O delineamento experimental foi em blocos casualizados com arranjo de parcelas subsubdivididas, onde os tratamentos foram dois sistemas manejo (plantio direto e convencional, nas parcelas) com doses de 0 e $2000 \mathrm{~kg} \mathrm{ha}^{-1} \mathrm{de}$ gesso (subparcelas) e cinco profundidades $(0-0,05,0,05-0,10$, $0,10-0,15,0,15-0,20$ e $0,20-0,30$ metros, sendo as subsubparcelas) com quatro repetições. Optou-se por considerar as profundidades estudadas como subsubparcelas, independente da casualização. Para as características agronômicas, o delineamento experimental utilizado foi em blocos casualizados, com quatro repetições em esquema experimental de parcelas subdivididas, sendo que as parcelas tiveram os sistemas de manejo e como subparcela à presença e ausência do efeito residual de gesso com quatro repetições.

Para coleta das amostras de solo, foram abertas trincheiras com dimensões de $0,50 \mathrm{~m}$ de largura por $0,50 \mathrm{~m}$ de comprimento e com $0,40 \mathrm{~m}$ de profundidade.

Para determinação dos atributos físicos do solo, foram coletadas três amostras indeformadas de solo por profundidade com anéis de aço de volume $100 \mathrm{~cm}^{-3}$, totalizando 12 repetições por tratamento em cada profundidade.

A densidade do solo foi determinada através do método do anel volumétrico, posteriormente, em laboratório. Determinou-se a porosidade total $(\mathrm{Pt})$, pela percentagem de saturação por água do solo. A microporosidade (Mi) e a macroporosidade do solo (Ma), foram determinadas pela mesa de tensão (Empresa Brasileira de Pesquisa Agropecuária-Embrapa, 1997).

A avaliação da resistência do solo à penetração a campo foi determinada usando o penetrógrafo SC-60 (soilcontrol), nas profundidades de $0-0,5,0,05-0,10,0,10$ $0,15,0,15-0,20,0,20-0,25,0,25-0,30,0,30-0,35,0,35-0,40$ e 
0,40-0,45 m. Foi mensurada a umidade do solo nas mesmas profundidades no mesmo dia do teste de resistência à penetração. O número de amostragem de resistência a penetração seguiu o descrito e recomendado por Tavares Filho \& Ribon, 2008.

A cultivar de soja usada foi a Coodetec 219, semeada em 29/10/2007. Sendo seu desempenho agronômico avaliado pelas seguintes características:

A altura de plantas, por ocasião da maturação a campo, foi determinada às vésperas da colheita, medindo-se 30 plantas por parcela. Essa determinação foi realizada considerando-se como altura da planta a distância entre a superfície do solo e a extremidade apical da haste principal da planta.

A altura de inserção da primeira vagem, medida entre a superfície do solo e o ponto de inserção da primeira vagem da haste principal, mediu-se 30 plantas por parcela.

O número de vagens foi obtido pela contagem de vagens de 30 plantas por parcela.

O peso de 100 grãos foi determinado após a mensuração da produtividade, quando foram contados e pesados em balança de precisão.

Para a determinação da produtividade, foram coletadas as vagens das plantas (individualmente), em uma área de $6 \mathrm{~m}^{2}$ no centro da parcela, as quais foram em seguida trilhadas. Os grãos trilhados foram limpos e a sua massa foi determinada, sendo os valores de massa de grãos obtidos, em cada parcela, transformados em kg ha-1, corrigidos a $13 \%$ de umidade.

A análise estatística, realizada sobre os sistemas de manejo, efeito residual de gesso, profundidade e na interação entre eles, quando mostrou significância pelo teste F, foi realizada, a comparação das médias feita pelo teste de Tukey a $5 \%$, por meio do programa de estatística ASSISTAT (Silva \& Azevedo, 2006).

\section{RESULTADOS E DISCUSSÃO}

A densidade do solo média no sistema de plantio direto foi significativamente maior do que no plantio convencional (Figura 1). Segundo Reichert et al. (2003), o valor restritivo de densidade, para Latossolos com teores de argila maiores que $70 \%$, é próximo de $1,40 \mathrm{~kg} \mathrm{dm}^{-3}$, entretanto o valor médio obtido neste trabalho foi de $1,21 \mathrm{~kg} \mathrm{dm}^{3}$ para o plantio direto, podendo dessa forma causar menor restrição ao crescimento das raízes. Os valores de densidade do solo no sistema plantio direto também foram inferiores aos citados por Beutler et al. (2006), que verificaram o efeito negativo da compactação na produtividade da cultura da soja. $\mathrm{O}$ acréscimo da densidade do solo no plantio direto pode ser atribuído ao menor revolvimento do solo associado com o tráfego de máquinas, implicando em uma maior justaposição dos agregados, o que torna o solo mais denso.

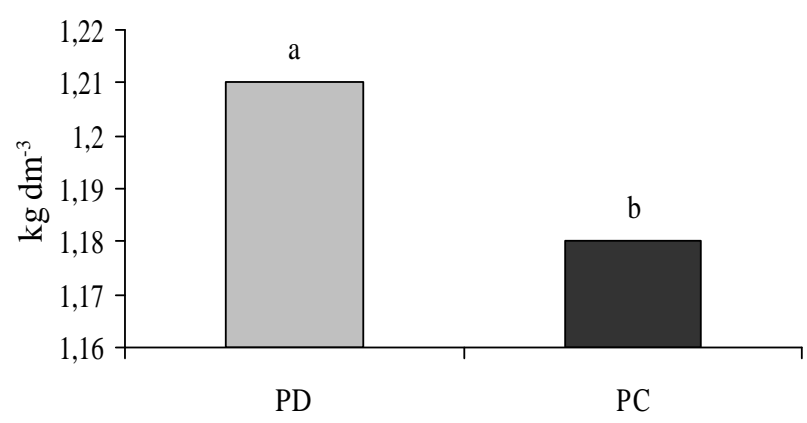

Figura $1-\mathrm{PD}=$ Plantio Direto, $\mathrm{PC}=$ Plantio Convencional. Valores médios de densidade de solo em função do manejo em Latossolo Vermelho Distroférrico no município de Dourados MS, 2008. Médias seguidas pela mesma letra, não diferem entre si pelo teste (F $5 \%$ ).

O efeito residual de gesso não proporcionou diferença significativa entre os sistemas de manejo do solo (Quadro 1), variando apenas dentro dos sistemas em diferentes profundidades. As profundidades com maiores valores médios de densidade do solo sem gesso estavam entre 0,05 a $0,20 \mathrm{~m}$ e o menor valor na profundidade mais superficial de 0-0,05 m. O menor valor médio de densidade do solo foi observado na profundidade entre 0-0,05 $\mathrm{m}$ na presença de gesso. Coube à disposição do efeito residual de gesso reduzir a densidade do solo. Rosa Junior et al. (2001) salienta que a redução da densidade do solo pode ser atribuída ao fato do gesso agir como agregante pelo fornecimento de cátions que neutralizariam parte das cargas negativas ocorrentes no meio e, portanto, proporcionariam condições de aproximação do ponto zero de carga.

Não houve efeito significativo entre o manejo do solo e efeito residual de gesso na porosidade total do solo (Figura 2). Entretanto, houve efeito entre profundidades. A porosidade total foi maior na camada de $0-0,05 \mathrm{~m}$ e menor na profundidade de 0,15-0,20 m. Thimóteo et al. (2001), avaliando dois sistemas de manejo do solo também constataram não haver efeito entre os manejos na porosidade total. Vale salientar que os valores de porosidade total obtidos foram superiores a 50\% considerado por Lima et al. (2007) como ideal. Provavelmente esta tendência de redução da porosidade total do solo com a profundidade deve-se ao acúmulo de pressões abaixo de $0,10 \mathrm{~m}$, resultante do tráfego de máquinas agrícolas. Rosa Junior (1994) comenta que a eluviação de partículas de argila é um dos fatores que causam aumento da densidade do solo, especialmente 
na camada de $0,08-0,15 \mathrm{~m}$ de profundidade, para o caso de Latossolos argilosos.

Houve efeito significativo na interação entre sistemas de manejo e profundidade na macroporosidade do solo (Quadro 2).

A macroporosidade do solo no plantio convencional (Quadro 2) foi significativamente maior do que no plantio direto na profundidade 0-0,05 m. Entretanto, nas demais profundidades não houve diferenças entre os manejos. Bergamin et al. (2010) obtiveram valores semelhantes para a profundidade de 0,0-0,05 $\mathrm{m}$ em plantio direto.

Mas, com o aumento da profundidade, a macroporosidade tendeu a diminuir em ambos os sistemas. Nas profundidades abaixo de $0,10 \mathrm{~m}$, a macroporosidade atingiu valores próximos a $10 \%$, considerados limitantes ao desenvolvimento das culturas conforme citam Vomocil \& Flocker (1961), Gupta \& Allmaras (1987), Engelaar \& Yoneyeama (2000) e Secco et al. (2004), indicando certo grau de compactação e menor difusão de oxigênio, além de influenciar no fluxo e na retenção de calor, afetando, dessa forma,o crescimento radicular.
Não houve alteração da microporosidade entre os sistemas de manejo (Quadro 2). A profundidade de 0-0,05 $\mathrm{m}$ apresentou menor valor de microporos tanto no plantio direto como no convencional. Os maiores valores de microporosidade foram observados nas profundidades de 0,05-0,30 m e 0,10-0,30 m para o PD e PC, respectivamente. A importância dos microporos na relação solo-água-planta está no fato destes armazenarem e reterem água no solo.

Houve efeito significativo da resistência do solo à penetração entre os sistemas de manejo do solo e também entre as profundidades (Quadro 3). Os valores de resistência a penetração aumentaram em maiores profundidades. Cabe ressaltar que, no momento da avaliação do nível de resistência, foi determinada a umidade gravimétrica do solo, devido ao conteúdo de água no solo influenciar diretamente em menor ou maior grau de resistência à penetração no solo. Colet et al. (2009) apresentam valores de o teor de água para as mesmas profundidades, indicando não haver diferença significativa, permitindo assim a comparação entre valores de resistência a penetração do solo. Uma vez que a resistência à penetração é altamente influenciada pelo teor de água no solo.

Quadro 1 - Desdobramento da interação entre efeito residual de gesso e profundidade para densidade do solo em Latossolo Vermelho distroférrico.

\begin{tabular}{|c|c|c|c|}
\hline Profundidade $(\mathrm{m})$ & $0 \mathrm{~kg} \mathrm{ha}^{-1}$ & $\mathrm{~kg} \mathrm{dm}^{-3}$ & $2000 \mathrm{~kg} \mathrm{ha}^{-1}$ \\
\hline $0-0,05$ & $1,08 \mathrm{aC}$ & & $1,06 \mathrm{aC}$ \\
\hline $0,05-0,10$ & $1,25 \mathrm{aA}$ & & $1,23 \mathrm{aAB}$ \\
\hline $0,10-0,15$ & $1,28 \mathrm{aA}$ & & $1,26 \mathrm{aA}$ \\
\hline $0,15-0,20$ & $1,24 \mathrm{aA}$ & & $1,22 \mathrm{aAB}$ \\
\hline $0,20-0,30$ & $1,19 \mathrm{aB}$ & & $1,18 \mathrm{aB}$ \\
\hline $\mathrm{Cv} \% \mathrm{~b}$ & & 5,79 & \\
\hline $\mathrm{Cv} \% \mathrm{c}$ & & 2,92 & \\
\hline
\end{tabular}

Médias seguidas pela mesma letra, minúscula na linha e maiúscula na coluna, não diferem entre si pelo teste de Tukey (p<0,05).

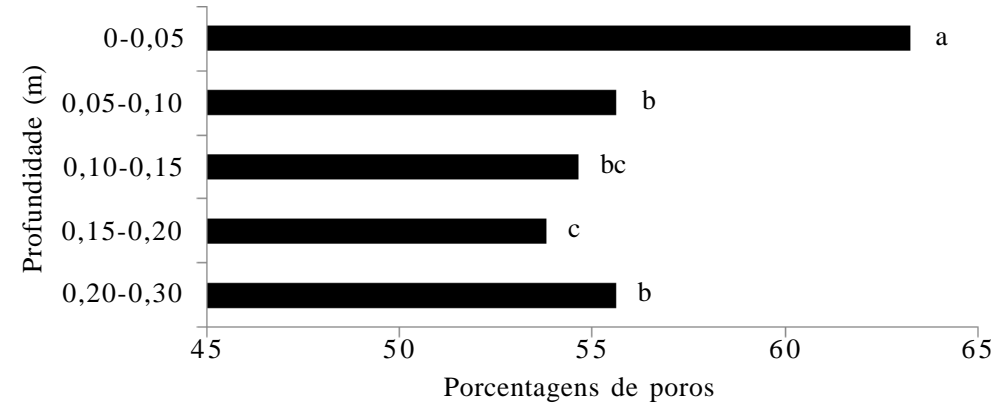

Figura 2 - Valores percentuais de poros do solo indiferente do manejo e efeito residual de gesso em profundidades. Médias seguidas pela mesma letra, não diferem entre si pelo teste de Tukey $(\mathrm{p}<0,05)$. 
Quadro 2 - Desdobramento da interação entre sistemas de manejo e profundidade para macroporosidade e microporosidade em um Latossolo Vermelho distroférrico.

\begin{tabular}{|c|c|c|c|c|}
\hline Profundidade $(\mathrm{m})$ & PD & $\mathrm{PC}$ & PD & $\mathrm{PC}$ \\
\hline & \multicolumn{2}{|c|}{ Macroporosidade (\%) } & \multicolumn{2}{|c|}{ Microporosidade (\%) } \\
\hline $0-0,05$ & $23,25 \mathrm{bA}$ & $27,18 \mathrm{aA}$ & $38,82 \mathrm{aB}$ & $37,19 \mathrm{aC}$ \\
\hline $0,05-0,10$ & $12,06 \mathrm{aB}$ & $14,21 \mathrm{aB}$ & $43,12 \mathrm{aA}$ & $41,86 \mathrm{aB}$ \\
\hline $0,10-0,15$ & $10,93 \mathrm{aB}$ & $10,97 \mathrm{aC}$ & $43,72 \mathrm{aA}$ & $43,68 \mathrm{aA}$ \\
\hline $0,15-0,20$ & $10,53 \mathrm{aB}$ & $9,92 \mathrm{aC}$ & $43,27 \mathrm{aA}$ & 43,88 aA \\
\hline $0,20-0,30$ & $11,17 \mathrm{aB}$ & $11,63 \mathrm{aBC}$ & $44,21 \mathrm{aA}$ & $44,22 \mathrm{aA}$ \\
\hline $\mathrm{Cv} \% \mathrm{a}$ & \multicolumn{2}{|c|}{19,26} & \multicolumn{2}{|c|}{7,10} \\
\hline $\mathrm{Cv} \% \mathrm{c}$ & \multicolumn{2}{|c|}{15,30} & \multicolumn{2}{|c|}{2,78} \\
\hline
\end{tabular}

$\mathrm{PD}=$ Plantio direto, $\mathrm{PC}=$ Plantio convencional. Médias seguidas pela mesma letra, minúscula na linha e maiúscula na coluna, não diferem entre si pelo teste de Tukey $(\mathrm{p}<0,05)$.

Quadro 3 - Valores médios da resistência a penetração do solo nos sistemas de manejo em diferentes profundidades e umidade gravimétrica do solo em diferentes profundidades submetido por ocasião da determinação da resistência do solo à penetração.

\begin{tabular}{|c|c|c|c|c|}
\hline \multirow[t]{2}{*}{$\begin{array}{c}\text { Sistemas } \\
\text { de manejo }\end{array}$} & \multicolumn{4}{|c|}{ Resistência a penetração do solo MPa } \\
\hline & $0-0,05$ & & & $0,10-0,15$ \\
\hline Plantio direto & $2,91 \mathrm{aA}$ & \multicolumn{2}{|c|}{$3,55 \mathrm{aB}$} & $3,70 \mathrm{aB}$ \\
\hline \multirow[t]{2}{*}{ Plantio Convencional } & $1,85 \mathrm{bA}$ & \multicolumn{2}{|c|}{$3,27 \mathrm{aB}$} & $3,65 \mathrm{aBC}$ \\
\hline & $0,15-0,20$ & \multicolumn{2}{|c|}{$0,20-0,25$} & $0,25-0,30$ \\
\hline Plantio direto & $3,84 \mathrm{aB}$ & \multicolumn{2}{|c|}{$3,95 \mathrm{aBC}$} & $4,10 \mathrm{aBCD}$ \\
\hline \multirow[t]{2}{*}{ Plantio Convencional } & $3,93 \mathrm{aCD}$ & \multicolumn{2}{|c|}{$4,12 \mathrm{aCDE}$} & $4,39 \mathrm{aDE}$ \\
\hline & $0,30-0,35$ & \multicolumn{2}{|c|}{$0,35-0,40$} & $0,40-0,45$ \\
\hline Plantio direto & $4,48 \mathrm{aCDE}$ & \multicolumn{2}{|c|}{ 4,66 aDE } & $4,85 \mathrm{aE}$ \\
\hline Plantio Convencional & $4,57 \mathrm{aE}$ & \multicolumn{2}{|c|}{$4,59 \mathrm{aE}$} & $4,64 \mathrm{aE}$ \\
\hline $\mathrm{Cv} \% \mathrm{a}$ & \multicolumn{4}{|c|}{31,19} \\
\hline \multirow[t]{5}{*}{$\mathrm{Cv} \% \mathrm{c}$} & \multicolumn{4}{|c|}{9,05} \\
\hline & \multicolumn{4}{|c|}{ Umidade gravimétrica do solo } \\
\hline & \multicolumn{4}{|c|}{ Profundidades $(\mathrm{m})$} \\
\hline & $0-0,10$ & $0,10-0,20$ & $0,20-0,40$ & $0,40-0,50$ \\
\hline & \multicolumn{4}{|c|}{$\%$} \\
\hline Plantio direto & 26,03 & 27,99 & 28,24 & 29,55 \\
\hline Plantio Convencional & 29,00 & 29,52 & 31,32 & 32,06 \\
\hline
\end{tabular}

Médias seguidas pela mesma letra, minúscula na coluna e maiúscula na linha, não diferem entre si pelo teste de Tukey $(\mathrm{p}<0,05)$.

Não houve diferença significativa entre a ausência e a presença residual de gesso. Considerando que a resistência à penetração limitante ao crescimento radicular é de $2 \mathrm{MPa}$ (Tormena et al., 1998; Silva et al., 2002; Beutler et al., 2006), observa-se, no Quadro 3, que as médias dos valores, em todas as profundidades, foram superiores a este valor, impondo certa restrição ao desenvolvimento radicular da cultura. O plantio convencional proporcionou menor RP do solo até a profundidade de 0,15 m (Quadro 3). 
A redução da RP na profundidade mais superficial, provavelmente, ocorreu devido ao revolvimento do solo pela ação da grade niveladora. Observa-se tanto no plantio direto como no convencional que houve tendência de aumento da compactação nas camadas mais profundas do solo, indicado pela maior RP.

O Quadro 4 apresenta os valores médios das características agronômicas nos sistemas de manejo. Não houve influência dos manejos para as variáveis alturas de planta, inserção de vagens, peso de 100 grãos e produtividade de grãos.

Observou-se efeito significativo para número de vagens (Quadro 4), em que se observa que o plantio convencional foi superior ao plantio direto, mas sem incremento na produtividade. Apesar de não haver diferença significativa na produtividade, observa-se que o rendimento foi semelhante ao obtido por Minuzzi et al. (2009), para mesma região.

A não diferenciação significativa entre os sistemas de manejo comprova que o solo, mesmo apresentando certo grau de compactação, não influenciou na produtividade. Miranda et al. (2005), comparando o plantio direto e o convencional, também não observaram diferenças significativas entre os manejos do solo na produtividade.

O efeito residual de gesso não proporcionou diferença significativa nas variáveis inserção de vagens, número de vagens, peso de 100 grãos e produtividade, (Quadro 5).

Observou-se efeito significativo do efeito residual do gesso apenas na altura de planta. Ressalta-se que a altura de planta é uma característica importante no crescimento das culturas, pois, plantas com porte muito alto podem acamar e plantas com porte muito baixo limitam o desempenho das máquinas na colheita.

A maior estatura na presença do efeito residual do gesso pode ter sido mais pronunciada devido ao menor grau de compactação do solo na presença desse condicionador, devido a maior agregação do solo, consequentemente melhorando a estrutura ou ainda pelo favorecimento químico com a presença de cálcio melhorando as condições de distribuição do sistema radicular.

Quadro 4 - Características agronômicas cultivar de soja Coodetec 219, em razão dos sistemas de manejo do solo em um Latossolo Vermelho distroférrico.

\begin{tabular}{|cccccc|}
\hline $\begin{array}{c}\text { Sistema de } \\
\text { Manejo }\end{array}$ & $\begin{array}{c}\text { Altura de planta } \\
(\mathrm{m})\end{array}$ & $\begin{array}{c}\text { Inserção de } \\
\text { vagens }(\mathrm{m})\end{array}$ & $\begin{array}{c}\text { Número de } \\
\text { vagens }\end{array}$ & $\begin{array}{c}\text { Peso de 100 } \\
\text { grãos }(\mathrm{g})\end{array}$ & $\begin{array}{c}\text { Produtividade } \\
\text { de grãos kg ha }^{-1}\end{array}$ \\
\hline PD & $0,82 \mathrm{a}$ & $0,26 \mathrm{a}$ & $40,71 \mathrm{~b}$ & $13,35 \mathrm{a}$ & $2309,43 \mathrm{a}$ \\
PC & $0,83 \mathrm{a}$ & $0,27 \mathrm{a}$ & $45,37 \mathrm{a}$ & $13,97 \mathrm{a}$ & $2414,28 \mathrm{a}$ \\
\hline $\mathrm{Cv} \% \mathrm{a}$ & & 2,95 & & \\
\hline
\end{tabular}

$\mathrm{PD}=$ Plantio direto, $\mathrm{PC}$ plantio convencional. Médias seguidas pela mesma letra, minúscula na coluna, não diferem entre si pelo teste de $\mathrm{F}(\mathrm{p}<0,05)$.

Quadro 5 - Características agronômicas da cultivar de soja Coodetec 219, sob efeito residual de gesso em um Latossolo Vermelho distroférrico.

\begin{tabular}{|cccccc|}
\hline $\begin{array}{c}\text { Gesso } \\
\left(\mathrm{kg} \mathrm{ha}^{-1}\right)\end{array}$ & $\begin{array}{c}\text { Altura de } \\
\text { planta }(\mathrm{m})\end{array}$ & $\begin{array}{c}\text { Inserção de } \\
\text { vagens }(\mathrm{m})\end{array}$ & $\begin{array}{c}\text { Número de vagens } \\
0\end{array}$ & $\begin{array}{c}\text { Peso de } 100 \\
\text { grãos }(\mathrm{g})\end{array}$ & $\begin{array}{c}\text { Produtividade } \\
\mathrm{kg} \mathrm{ha}^{-1}\end{array}$ \\
2000 & $0,85 \mathrm{~b}$ & $0,25 \mathrm{a}$ & $42,82 \mathrm{a}$ & $13,82 \mathrm{a}$ & $2311,56 \mathrm{a}$ \\
\hline $\mathrm{Cv} \% \mathrm{~b}$ & $0,28 \mathrm{a}$ & $43,26 \mathrm{a}$ & $13,50 \mathrm{a}$ & $2412,15 \mathrm{a}$ \\
\hline
\end{tabular}

Médias seguidas pela mesma letra, minúscula na coluna, não diferem entre si pelo teste de $\mathrm{F}(\mathrm{p}<0,05)$. 


\section{CONCLUSÕES}

A densidade do solo média foi maior no plantio direto. A macroporosidade foi maior na profundidade de 0-0,05 m no plantio convencional e a microporosidade aumentou, com a profundidade, nos dois sistemas de manejo. A resistência à penetração aumentou em profundidade. $\mathrm{O}$ sistema de plantio direto proporcionou menor número de vagens e o gesso agrícola, proporcionou maiores valores de altura final das plantas.

\section{REFERÊNCIAS BIBLIOGRÁFICAS}

BAYER, C.; MIELNICZUK, J.; SANTOS, S.R. Física do solo, diagnóstico e manejo da compactação em plantio direto. In: FONTOURA, S.M.V.; BAYER, C. Manejo e fertilidade de solos em plantio direto. Guarapuava: Fundação Agrária de Pesquisa Agropecuária, 2006. 218p.

BENGOUGH, A.G.; CAMPBELL, D.J.; O'SULLIVAN, M.F. Penetrometer techniques in relation to soil compaction and root growth. In: SMITH, K.A.; MULLINS, C.E. (Eds.). Soil environmental analysis: physical methods. 2.ed. Madison: M. Decher, 2001. p.377-403.

BERGAMIN, A.C.; VITORINO, A.C.T.; FRANCHINI, J.C.; SOUZA, C.M.A.; SOUZA, F.R. Compactação em um Latossolo vermelho distroférrico e suas relações com o crescimento radicular do milho. Revista Brasileira de Ciência de Solo, Viçosa, v.34, n.3, p.681-691, 2010.

BEUTLER, A.N.; CENTURIUON, J.F.; CENTURION, M.A.P.C.; SILVA, A.P. Efeito da compactação na produtividade de cultivares de soja em Latossolo Vermelho. Revista Brasileira de Ciência de Solo, Viçosa, v.30, p.787-794, 2006.

COLET, M.J.; SVERZUT, C.B.; WEIRICH NETO, P.H.; SOUZA, Z.M. de. Alteração em atributos físicos de um solo sob pastagem escarificado. Ciência e

Agrotecnologia, Lavras, v.33, n.2, p.361-368. 2009.

COSTA, E.A.; GOEDERT, W.; SOUSA, D.M.G. Qualidade de solo submetido a sistemas de cultivo com preparo convencional e plantio direto. Pesquisa Agropecuária Brasileira, Brasília, v.41, n.7, p.1185-1191, 2006.

COSTA, M.J.; ROSA JUNIOR, E.J.; ROSA, Y.B.C.J.; SOUZA, L.C.F.; ROSA, C.B.J. Atributos químicos e físicos de um Latossolo sendo influenciados pelo manejo do solo e efeito da gessagem. Acta Scientiarum Agronomy, Maringá v.29, p.701-708, 2007.
EMPRESA BRASILEIRA DE PESQUISA

AGROPECUÁRIA. Centro Nacional de Pesquisa de Solos. Manual de métodos de análises de solo. 2.ed. Rio de Janeiro, 1997. 212p.

ENGELAAR, W.M.H.G.; YONEYAMA, T. Combined effects of soil waterlogging and compaction on rice (Oryza sativa L.) growth, soil aeration, soil N transformations and $\mathrm{N}$ discrimination. Biology and Fertility of Soils, v.32, p.484-493, 2000.

GUPTA, R.K.; NARESH, R.K.; HOBBS, P.R.; LADHA, J.K. Adopting conservation agriculture in the rice-wheat system of the Indo-Gangetic Plains: new opportunities for saving water. In: BOUMAN, B.A.M.; HENGSDIJK, H.; HARDY, B.; BINDRABAN, P.S.; TUONG, T.P.; LADHA, J.K. (Eds.). Water wise rice production: proceedings of the international workshop on water wise rice production. Los Banos: International Rice Research Institute, 2002. p.207-222.

GUPTA, S.C.; ALLMARAS, R.R. Models to assess the susceptibility of soils to excessive compaction. Advanced in Soil Science, New York, v.6, n.1, p.65-100, 1987.

HOBBS, P.R.; GUPTA, R.K. Rice-wheat cropping systems in the Indo-Gangetic Plains: issues of water productivity in relation to new resource-conserving technologies. In: KIJNE, J.W.;BARKER, R.; MOLDEN, D. (Eds.). Water productivity in agriculture: limits and opportunities for improvement. Wallingford: CABI, 2003. p.239-253.

LIMA, C.G.R.; CARVALHO, N.P.; MELLO, L.M.N.; LIMA, R.C. Correlação linear espacial entre a produtividade de forragem, porosidade total e a densidade do solo de Pereira Barretos (SP). Revista Brasileira de Ciência do Solo, Viçosa, v.31, p.1233-1244, 2007.

MARIA, I.C. de; CASTRO, O.M.; DIAS, H.S. Atributos físicos do solo e crescimento radicular de soja em Latossolo Roxo sob diferentes métodos de preparo do solo. Revista Brasileira de Ciência de Solo, Viçosa, v.23, p.703-709, 1999.

MINUZZI, A.; RANGEL, M.A.S.; BRACCINI, A. de L. e; SCAPIM, C.A.; MORA, F.; ROBAINA, A.D.

Rendimento, teores de óleo e proteínas de quatro cultivares de soja, produzidas em dois locais no estado do Mato Grosso do Sul. Ciência e Agrotecnologia, Lavras, v.33, n.4, p. 1047-1054, jul./ago., 2009. 
MIRANDA, L.N.; MIRANDA, J.C.C.; REIN, T.A.; GOMES, A.C. Utilização de calcário em plantio direto e convencional de soja e milho em Latossolo Vermelho. Pesquisa Agropecuaria Brasileira, Brasília, v.40, n.6, p.563-572, 2005.

RAIJ, B.V. Gesso na agricultura. Campinas: Instituto Agronômico, 2008. 233p.

REICHERT, J.M.; REINERT, D.J.; BRAIDA, J.A. Qualidade dos solos e sustentabilidade de sistemas agrícolas. Revista Ciência \& Ambiente, Santa Maria, v.27, p.29-48, 2003.

ROSA JUNIOR, E.J.; CREMON, C.; MARTINS, R.M.G.; RODRIGUES, E.T. Gesso e calcário como condicionadores de atributos de um Latossolo sob cultivo de soja-milho. Cerrados Revista de Ciências Agrárias, Campo Grande, v.2/4, n.3/8, p.45-50, 2001.

ROSA JÚNIOR, E.J.; MARTINS, R.M.G.; ROSA, Y.B.C.J.; CREMON, C. Calcário e gesso como condicionantes físico e químico de um solo de cerrado sob três sistemas de manejo. Pesquisa Agropecuária Tropical, Goiânia, v.36, p.37-44, 2006.

ROSA JUNIOR, E.J.; VITORINO, A.C.T.; VITORINO, P.F.P. Efeito da calagem, gessagem e adubação fosfatada sobre algumas características físicas de um Latossolo Roxo Distrófico de Dourados, MS. Revista Científica, Campo Grande, v.1, n.1, p.5-12, 1994.

SECCO, D.; REINERT, D.J.; REICHERT, J.M.; ROS, C.. Produtividade de soja e propriedades físicas de um Latossolo submetido a sistemas de manejo e compactação. Revista Brasileira de Ciência do Solo, Viçosa, v.28, p.797-804, 2004.

SILVA, A.P.; TORMENA, C.A.; IMHOFF, S. Intervalo hídrico ótimo. In: MORAES, M.H.; MÜLLER, M.M.L.; FOLONI, J.S.S. Qualidade física do solo: métodos de estudo-sistemas de preparo e manejo do solo. Jaboticabal: Funep, 2002. p.1-18.
SILVA, F.A.S.; AZEVEDO, C.A.V. A new version of the assistat-statistical assistance software. In: WORLD CONGRESS ON COMPUTERS IN AGRICULTURE, 4., 2006, Orlando. Proceedings... Orlando: American Society of Agricultural Engineers, 2006. p.393-396.

SPERA, S.T.; SANTOS, H.P.; FONTANELI, R.S.; TOMM, G.O. Efeitos de sistemas de produção de grãos envolvendo pastagens sob plantio direto nos atributos físicos de solo e na produtividade. Revista Brasileira de Ciência do Solo, Viçosa, v.28, p.533-542, 2004.

TAVARES FILHO, J.; RIBON, A.A. Resistência do solo à penetração em resposta ao número de amostras e tipo de amostragem. Revista Brasileira de Ciência do Solo, Viçosa, v.32, p.487-494, 2008.

TAYLOR, H.; GARDNER, H. Penetration of cotton seedling taproots as influenced by bulk density, moisture content, and strength. Soil Science Society of America Journal, Madison, v.963, p.153-156, 1963.

THIMÓTEO, C.M.S.; BENINI, E.R.Y.; MURATA, I.M.; TAVARES FILHO, J. Alterações da porosidade e da densidade de um Latossolo Vermelho Distrófico em dois sistemas de manejo de solo Acta Scientiarum Agronomy, Maringá, v.23, n.5, p.1299-1303, 2001.

TORMENA, C.A.; SILVA, A.P.; LIBARDI, P.L. Caracterização do intervalo hídrico ótimo de um latossolo roxo sob plantio direto. Revista Brasileira de Ciência do Solo, Viçosa, v.22, n.4, p.573-581, 1998.

VITTI, C.G.; LUZ, P.H.C.; MALAVOLTA, E.; DIAS, A.S.; SERRANO, C.G.E. Uso do gesso em sistemas de produção agrícola. Piracicaba: GAPE, 2008. 104p.

VOMOCIL, J.A.; FLOCKER, W.J. Effect of soil compaction on storage and movement of soil air and water. Transaction of the ASAE, Saint Joseph, v.4, p.242246, 1961. 